\title{
Serum Uric Acid Level in Preeclamptic Women Determine the Severity of Preeclampsia
}

\author{
KHAIRUN NAHAR ${ }^{1}$, SAYADA FATEMA KHATUN ${ }^{2}$, NAILAATIK KHAN ${ }^{3}$
}

\begin{abstract}
s:
Background: Serum uric acid is a relatively insoluble metabolite of purine metalolism which is mainly secreted by the kidneys and the rate is dependant on renal blood flow. It increases in preeclampsia and studies show it may be marker of severe preeclampsia.

Methods and materials: This cross sectional study was conducted in Dhaka Medical College Hospital in eclampsia ward of gynae \& Obs department during the period from January 2010 to December 2011 with the objective to determine the serum uric acid level in preeclampsia, to compare the serum uric acid level between mild and sever preeclampsia and to find out any relationship of the serum uric acid level with hypertension in preeclampsia. The study group composed of 92 diagnosed case of preeclampsia patient. Out of the 92 cases, 42 had mild preeclampsia (group-A) and 50 had severe preeclampsia (group B).
\end{abstract}

Result: The results of the study showed that the mean serum uric acid level was significantly higher in severe preeclampsia $(6.91+1.02)$ compared to mild preeclampsia $(4.99+0.80)$ and there is a positive and significant relationship of serum uric acid level with severity of hypertension in preeclampsia $(p<.0001)$.

Conclusion: There is significant association between serum uric acid level and severity of hypertension in Preeclampsia.

Key word: Uric acid level in preeclampsia, Severity of preeclampsia.

\section{Introduction:}

Pregnancy induced hypertention is one of the most significant health problem in pregnancy. $\mathrm{PIH}$ mainly preeclamosia complicates 6 to $8 \%$ of all pregnancies. ${ }^{1}$ It is the leading cause of fetal growth retardation and infant morbidity and mortality. It is responsible for $16 \%$ of maternal mortality and $28 \%$ of perinatal mortality. ${ }^{2}$ Despite the advancement in the field of medicine, preeclampsia/eclampsia still remains the the third leading cause of maternal mortality. ${ }^{3}$ Pre eclampsia is a multisystem disorder of unknown etiology characterized by development of hypertension to the extent of $140 / 90 \mathrm{mmHg}$ or more with proteinuria after $20^{\text {th }}$ week of pregnancy in a previously normotensive and non-proteinuric patient ${ }^{4}$. Preeclampsia is known as "the disease of multiple theories". Among them genetic, immunological, circulatory factor, uterine vascular changes and endothelial dysfunction are important. ${ }^{5}$ Although inflammation and extensive endothelial dysfunction of vessels are the main possible mechanism of preeclampsia but the pathogenesis of this syndrome has not been well understood. Renal involvement has been seen and recognised by many observers that some changes to severe damage can occur $^{6}$. Impairment of renal function is a probable pathogenesis for preeclampsia. Renal perfusion and glomerular filtration are reduced. This hampers the excretion of the metabolic waste products mainly urea $\&$ creatinine, the secretion of the uric acid and cause the loss of non selective plasma protein. All these lead to elevation of serum cretinine, blood urea, uric acid, proteinuria and changes in the urinary sediment ${ }^{7}$. The most commonly accpted explanation for hyperuricemia is increased reabsorption and decreased excretion of uric acid. ${ }^{8}$ There was no screening test reliable enough to diagnose

1. Medical Officer, Department of Gynaecological Oncology, BSMMU.

2. Consultant, Department of Gynaecological Oncology, BSMMU.

3. Medical Officer, Department of Biochemistry and Molecular Biology, BSMMU.

Address of Correspondence : Dr. Khairun Nahar, Medical Officer, Dept. of Obs \& Gynae, BSMMU, Shahbag, Dhaka1000, Email: khairun_nahar58@yahoo.com, Mobile : 01717220429 
preeclampsia. Uric acid is one of the most sensitive indicators of disease severity in pregnancy induced hypertensive disorders and can be of great in monitoring the cause of disease process. ${ }^{9}$ The degree of hyperuricaemia in PE reflects the severity of the disorder. ${ }^{10}$ Serum uric acid is not only a marker of severity of disorder but also contributes to the pathology of disorder ${ }^{11}$. Redman et al have suggested that patients who subsequently develop preeclampsia have significantly higher level of uric acid from 28 weeks of gestation ${ }^{12}$. Elevated serum uric acid concentration were first noted in preeclamptic women in the late $1800 s^{13}$. Since that time numerous reports have demonstrated a relationship between uric acid concentration and severity of disease ${ }^{14,15}$. Hyperuricemia was present in $16 \%$ of women with gestational hypertension without proteinuria and $75 \%$ of women with clinically diagnosed $\mathrm{PE}^{13}$. In women who go on to develop preeclampsia, uric acid concentration is elevated as early as 10 weeks of gestation, a time much earlier than the clinical presentation of the disorder ${ }^{16}$. There are limited study in our country about this. The aim of my study was to determine the early detection of raised serum uric acid level in preeclamptic women as a predictor of severity of PE and to prevent the maternal and fetal complication.

\section{Materials and Methods:}

This study carried out at Dhaka Medical College Hospital. There were 92 diagnosed case of preeclamptic patients taken in this study. Out of 92 cases 42 were mild pre-eclampsia that were classified as group $A$ and 50 were severe pre-eclampsia that were classified as group B. Mild PE patient was selected as a systolic $B P \geq 140 \mathrm{mmHg}$ but $<160 \mathrm{mmHg}$ and diastolic $B P \geq 90 \mathrm{mmHg}$ but $<110 \mathrm{~mm} \mathrm{Hg}$ and proteinuria( $\geq 1+$ or more by dip stick test). Severe PE were selected as a systolic $B P \geq 160 \mathrm{mmHg}$ and diastolic $B P \geq 110 \mathrm{mmHg}$ along with proteinuria(3+ or more by dip stick test). Patients with pre existing hypertention, cardiovascular disease, renal disease, liver disease, thyroid disease, diabetes mellitus and patient with acute or chronic illness were excluded from the study. All patients enrolled in this study were explained about the nature and purpose of the study. An informed written consent was taken from each of them. All data were recorded in a preformed questionnaire. The clinical examination was done by standard method. Blood pressure was measured by same sphingomanometer in sitting position. Two measurements were taken out in 4 hours apart. From each patients $5 \mathrm{cc}$ of blood was collected under asceptic precaution from the antecubital vein with disposible plastic syringe and was transferred to a dry clean test tube. Blood was sent to analyze the serum uric acid level in the bio chemistry department. Ten $\mathrm{ml}$ of mid stream urine was collected in a test tube from the study subjects. Serum uric acid was measured by enzymetic method ${ }^{17}$. Uric acid in the sample is oxidized to allantoine and hydrogen peroxide in the presence of uricase. The liberated hydrogen peroxide is detected by chromogenic oxygen acceptor in the presence of peroxidase. The red quinine formed is proportional to the amount of uric acid present in the sample. Urinary albumin was measured by dipstick method using reagent strip ${ }^{18}$. Fresh, well mixed, uncentrifused urine specimen was collected for the test. The colour is compared with the colour chart provided, which indicates the approximate protein concentration. The data collected were compiled with the help of a personal computer and appropriate statistical analysis was carried out using SPSS program. Students $t$ test and chi- square test were done to compare the results between the different groups. The difference was considered significant when the $p$ value was $<0.05$. The results were shown in the form tables.

\section{Result:}

Among all preeclamptic women mean $( \pm S D)$ age of mild preeclampsia $(29.14 \pm 4.39$ years) was significantly higher $(\mathrm{P}<0.01)$ than severe preeclampsia $(25.78 \pm 4.91$ years $)$. In severe preeclampsia, significantly higher $(P<0.01)$ number of women belonged to age group $<30$ years $(78 \%)$.(Table-I). The difference of gravidity among study subjects showed that in mild preeclampsia all 42(100\%) women were multigravida, while in severe preeclampsia $20(40 \%)$ were primigravida and $30(60 \%)$ multigravida. Statistically the distribution was highly significant $(P<0.001)$ (TableI). The present study showed comparsion and distribution of gestational age between the two study groups. The difference of gestational age was not statistically significant. Mean $( \pm S D)$ gestational age in mild and severe preeclampsia were $(31.74 \pm 3.80)$ and $(33.06 \pm 3.07)$ respectively.

Level of serum uric acid in the study was significantly higher $(P<0.001)$ in severe $P E(6.91 \pm 1.02) \mathrm{mg} / \mathrm{dl}$ compared to mild $P E(4.99 \pm 0.80) \mathrm{mg} / \mathrm{dl}$. 
Table-I

Age, gravidity and gestational age distribution of study subjects

\begin{tabular}{|c|c|c|c|}
\hline Age (years) & Group A $(n=42)$ & Group $B(n=50)$ & Pvalue $^{a}$ \\
\hline$\overline{M e a n \pm S D}$ & 29.144 .39 & 25.784 .91 & $0.001^{* *}$ \\
\hline \multirow[t]{2}{*}{ Range } & 20.00.35.00 & 19.00 .35 .00 & \\
\hline & $(\%)$ & $(\%)$ & Pvalue $^{b}$ \\
\hline$<30$ & $(45.2)$ & $(78.0)$ & $0.001^{* *}$ \\
\hline $30-40$ & $(54.8)$ & $(22.0)$ & \\
\hline Gravidity & & & Pvalue ${ }^{a}$ \\
\hline MeanSD & \multirow[b]{2}{*}{2.00 .8 .00} & 2.36 .63 & $0.001^{* *}$ \\
\hline Range & & $1.00-6.00$ & \\
\hline No. & $(\%)$ & $(\%)$ & Pvalue \\
\hline Primi & 0 & $(40.0)$ & $0.0001^{* * *}$ \\
\hline Multi & $(100.0)$ & (60.0) & \\
\hline Gestational age (weeks) & & \multirow{3}{*}{$\begin{array}{c}33.06 .07 \\
27.00-40.00\end{array}$} & Pvalue ${ }^{a}$ \\
\hline \multirow[t]{3}{*}{ MeanSD Range } & \multirow{2}{*}{$\begin{array}{c}31.74 .80 \\
23.00 .38 .00\end{array}$} & & $0.068^{\mathrm{ns}}$ \\
\hline & & & \\
\hline & $(\%)$ & $(\%)$ & Pvalue ${ }^{b}$ \\
\hline$\leq 34$ & $(81.0)$ & (72.0) & $0.316^{\text {ns }}$ \\
\hline$>34$ & $(19.0)$ & $(28.0)$ & \\
\hline
\end{tabular}

Group A : Mild preeclampsis

Group B : Severe preeclampsia

aUnpaired Student's 't' test

${ }^{\mathrm{b}} \mathrm{Chi}$-square test

${ }^{* *}=$ Significant at $P<0.001$

$* * *=$ Significant at $\mathrm{P}<0.0001$

Ns $=$ Not Significant

Table-II

Status of serum uric acid

\begin{tabular}{lccc}
\hline & Group $\mathrm{A}(\mathrm{n}=42)$ & Group B $(\mathrm{n}=50)$ & Pvalue $^{\text {a }}$ \\
\hline Serum uric acid $(\mathrm{mg} / \mathrm{dl})$ & & & \\
MeanSD & 4.99 .80 & 6.91 .02 & $0.0001^{* * *}$ \\
Range & $3.20-6.21$ & $5.03-8.83$ & \\
\hline
\end{tabular}

Group A : Mild preeclampsis

Group B : Severe preeclampsia

aUnpaired Student's 't' test

$* * *=$ Significant at $\mathrm{P}<0.001$

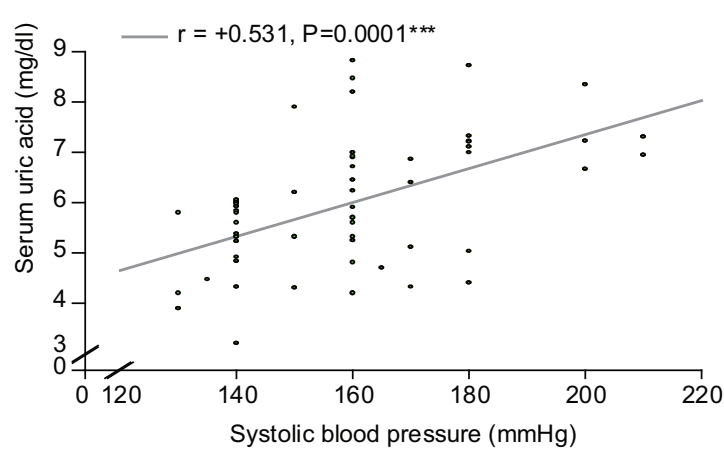

Fig.-1: Effect of systolic blood pressure on serum uric acid level.

69

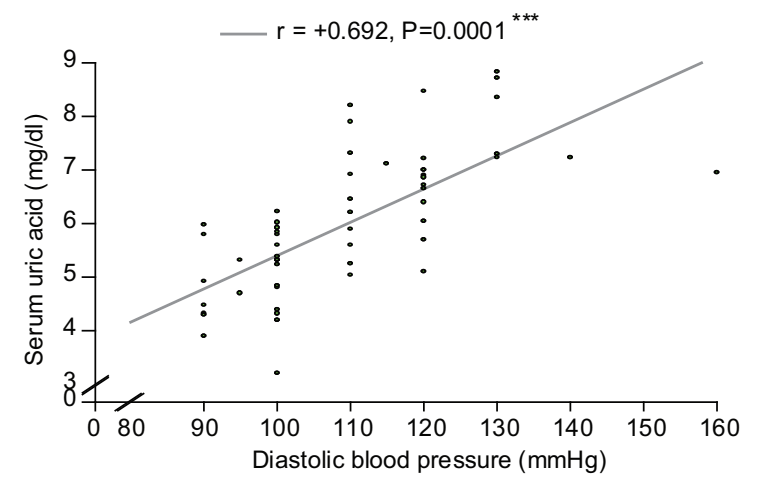

Fig.-2: Effect of diastolic blood pressure on serum uric acid level. 
Figures $(1+2)$ show that both systolic $(r=+0.53$, $p<.0001)$ and diastolic $(r=+0.69, p<.0001)$ blood pressure have positive and significant positive correlation with serum uric acid levels.

\section{Discussion:}

Status of serum uric acid in this study shows that mean $( \pm S D)$ serum uric acid was significantly $\operatorname{high}(p<0.001)$ in severe PE compared to mild PE . Both systolic and diastolic blood pressure have positive and significant $(r=+0.531, p<0.001)$ and $(r=+0.692, p<0.001)$ effect on serum uric acid level. The results are similar with other studies. Punthumapol, and Kittichotpanich ${ }^{19}$ conducted a case control study to evaluate serum uric acid level in mild and severe preeclamptic and normal pregnant women. The result showed that in severe preeclamptic women the serum uric acid was significantly higher than in normal pregnant women and mild preeclamptic women respectively but there was no difference between normal and mild preeclamptic women. Hyperurecemia correlated to severe preeclamptia. Suchanda studied to assess serum uric acid concentration in preeclamptic and normal pregnancy. The study comprised of 30 normal and 30 preeclampsia cases in their third trimester of pregnancy. There was an increase in both serum and urine uric acid levels in cases though the urinary $\mathrm{pH}$ in both the groups were similar ${ }^{20}$. Kharb studied uric acid level in pregnancy with preeclampsia and diabetes. Study done on 40 preeclamptic patients (18 diabetic women) (DM-PRW) \& 22 without diabetes (PRW) and 20 normotensive pregnant women( 8 with gestatational diabetes \& rest 12 were healthy preeclamptic women) and control group consisting of 20 healthy nonpregnant women. Study result showed that serum uric acid value were significantly increased in PRW \& DM-PRW as compared to controls and were higher in PRW than DM-PRW $(p>0.05) .{ }^{21}$

A study between preeclampsia, pregnancy induced hypertension and normal pregnant women showed that serum uric acid and creatinine levels were significantly elevated in $\mathrm{PE}$ ( $6.26 \pm 1.19$ and $0.94 \pm 0.26$ $\mathrm{mg} / \mathrm{dl}$ ) when compared with pregnancy induced hypertension $(\mathrm{PIH})(4.27 \pm 1.0$ and $0.66 \pm 0.19 \mathrm{mg} / \mathrm{dl})$ and $\mathrm{NP}(4.25 \pm 0.8 \text { and } 0.63 \pm 0.13 \mathrm{mg} / \mathrm{dl})^{22}$.

A study was done on normal pregnant women attending clinic at Nnamdi Azikiwe University Teaching Hospital Nnewi Nigeria. Serum uric acid was determined in 200 women attending antenatal clinic between the gestational ages of 14 and 26 weeks. The women were followed up at 2 weekly intervals until 36 weeks and weekly there after until delivery. Women who developed preeclampsia or eclampsia were identified. Pregnancy outcome were determined as well as fetal and placental weights. Result showed that $10.5 \%$ of the women developed preeclampsia. The positive and negative predictive values of serum uric acid for preeclampsia were $78.9 \%$ and $97.1 \%$ respectively. ${ }^{23}$

Study done by Toshniwal et al , observation showed significant difference between the two forms of preeclampsia i.e.,mild and severe and $\mathrm{PIH}$ suggesting uric acid to be a good marker of severity of disease. ${ }^{24}$ Another study done by Dekker, Sibai found that serum uric acid is a poor predictor of preeclampsia. ${ }^{25}$ Thangaratinam, Ismail also found that serum uric acid is a poor predictor of maternal and fetal complication in women with preeclampsia. ${ }^{26} \mathrm{~A}$ study done by Keith and France showed that significant elevation in serum uric acid level over normotensive pregnant women was observed in both the gestational hypertensive group and the preeclamptic group of women. Serum uric acid levels were also significantly elevated in women with gestational hypertention with HELLP syndrom compared to those without HELLP syndrom. Preeclamptic women with HELLP syndrome also demonstrated elevated uric acid levels over those without HELLP syndrome ${ }^{27}$. Study done by Patel and Dudhat showed that hyperuricemia in patients with hypertensive disorder of pregnancy is a strong risk factor for several maternal and perinatal complications $^{28}$. Another study showed that uric acid has been associated for long with preeclampsia and it is of simple and inexpensive determination ${ }^{29}$. A study performed in women with gestational hypertension and found that preeclampsia was diagnosed on average, 14.7 days after detection of hyperuricemia ${ }^{30}$. Study done by Sadia,Sharmin, Sheema showed that mean $( \pm S D)$ serum uric acid was significantly elevated in severe preeclampsia and eclampsia patients compared to normotensive pregnancy. Study also showed that there was positive and statistically significant relationship between diastolic blood pressure and hyperuricaemia in severe preeclampsia and eclampsia patients ${ }^{31}$. There is another study which showed that serum uric acid was $\geq 6 \mathrm{mg} / \mathrm{dl}$ in $63.5 \%$ among all preeclamptic women. There was positive and significant association between means of serum 
uric acid at different levels of hypertension. Study also revealed significant association between increase level of serum uric acid and bad fetal outcome ${ }^{32}$.

Pre eclampsia is a serious complication of the second half of pregnancy. This is a leading cause of fetal growth retardation, infant mortality, morbidity and maternal death. Women with PE are at increased risk for such complication like abruptio placentae, acute renal failure, cerebral haemorrhage, disseminated intravascular coagulation, pulmonary edema, circulatory collapse and eclampsia 33 (Redman, 1993). Although inflammation and extensive endothelial dysfunction of vessels are the main possible mechanism of preeclampsia but the pathogenesis of this syndrome has not been well understood. However evidence accumulated in the past 20 years indicates that in a larger number of these women abnormal placentation is one of the initial event. Some of the main features of abnormal placentation are inadequate trophoblastic invasion of the maternal spiral arteriols and accelerated apoptosis of the trophoblast with abundant release of fetal DNA into maternal circulation ${ }^{34}$ (Arias 2008). The anatomic and physiologic disruption of normal placentation is thought to lead to the synthesis of products that affect angiogenesis and to abnormal lipid peroxidation. With the advance in gestation, these products will affect the endothelial system with the production of signs and symptoms of multiple organ compromise ${ }^{34}$.

Uric acid is a marker of oxidative stress, tissue injury and renal dysfunction. It is possible that uric acid merely identifies a more severe form of pre eclampsia ${ }^{35}$. Uric acid is synthesized by the enzyme xanthine oxidase and in human most circulating uric acid is produced in the liver. Serum uric acid levels normally decreased at the beginning of pregnancy, remain low during $2^{\text {nd }}$ trimester and slowly increased during the $3^{\text {rd }}$ trimester, nearly reaching nonpregnant levels at term ${ }^{36}$ (Fernado,1993). The explanation for the increase in serum uric acid has been primarily secondary to reduced renal urate clearance because of renal dysfunction ${ }^{37}$ (Conred,1999).A monitoring opinion suggests increased uric acid is a marker of increased xanthine oxidase activity. Serum uric acid level is taken as sensitive indicator of preeclampsia and the abnormal values are elevated above $6 \mathrm{mg} / \mathrm{dl}$. The degree of hyperuricaemia in PE reflects the severity of the disorder.

Early identification of biochemical marker of the disease would not only facilitate to diagnose the severity of PE but also help in determining those patient who were more likely to benefit from therapeutic intervention and to prevent progress to eclampsia. So this study is done for early detection of severe preeclampsia. The result of the current study when considered with those of others, suggested that there is a relationship between severity of hypertension with serum uric acid level.

\section{Conclusion:}

Serum uric acid has positive and significant relationship with the blood pressure and the relationship in severe preeclampsia is more significant than the mild preeclampsia. So, serum uric acid level in preeclamptic women determine the severity of preeclampsia.

\section{References:}

1. Norwiz ER, Robinson JN, Rapke JT. Prevention of preeclampsia : is it possible ? clin obstet gynaecol 1999; 422-436.

2. Shamsuddin, L., Rouf, S., Katun, H. Perinatal outcome of Eclampsia patients. Bangladesh J Obstet Gynaecol.1995; 10:65-72.

3. Soule L. Hypertensive disorders of pregnancy. In: Manual of Gynaecology and Obstetrics. Bankowski BJ, Hearne AE, Lambrou NC, Fox HE, Wallach EE (eds). $2^{\text {nd }}$ ed. Philadelphia, Lippincott Williams and Wilkins, 2002, pp 183-93.

4. Dutta D. Hypertensive disorder in pregnancy. In: Textbook of Obstetrics including perinatology and contraception. Konar $\mathrm{H}(\mathrm{ed}) .6^{\text {th }}$ ed. New Central Book Agency, New Delhi, 2004, p 222.

5. Reynolds C, Mabie WE, Sibaj BW. Hypertensive states of pregnancy. In: Current Obstetric and Gynaecologic Treatment. Dechenry AH, Nathan $L$ (eds). $9^{\text {th }}$ ed. New York, Lange Medical Books, McGraw-Hill, 2003, pp 338-53.

6. Miller DA. Hypertension in pregnancy. In: Current Obstetric and Gynaecologic diagnosis and treatment. De chenrey AH, Goodwin TM, Nathan L, Laufer N (eds). $10^{\text {th }}$ ed. McGrawnHHI, New York, 2007, pp 318-27.

7. Shashnak VP, Rashms P. Pregnancy-induced hypertension: Current concepts. In: Pregnancy at risk current concepts. Krishna U, Tank DK, Daftary S, Pvij J. $4^{\text {th }}$ ed. New Delhi, Jaypee Brothers Medical Publishers Ltd. 2004, pp 257-62.

8. Many A, Hubel CA, Roberts JM. Hyperuricemia and xanthine oxidase in preeclampsia. Am J Obstet Gynecol. 1996;174;220-91.

9. Soomro N, Shazia. Serum uric acid as a predictor model for preeclampsia. Pak J Surg. 2010; 26(3);246-51. 
10. Ihle B.U., Long, P.,Oats ,J. Early onset Preeclampsia: recogn ition of underlying renal disease. British Medical Journal. 1987; 294.

11. Bainbridge SA, Roberts JM. Uric acid as a pathogenic factor in preeclamptic placenta. 2008; 22: S67- S72.

12. Redman CWG, Bellin J, Bonnar J. Renal function in preeclampsia. J Clin Path. 1976; 10: 91-94.

13. Shannon A, James M. Uric Acid as a pathogenic factor in preeclampsia.PMC. 2018;29: 567-572.

14. Voto LS, Illia R, Darbon-Grosso HA, ImazFU, Margulies M. Uric acid levels: a useful index of the severity of preeclampsia and perinatal prognosis. J Perinat Med. 1988; 16: 123-6.

15. Roberts JM, Bodnar LM, Lain KY, Hubel CA, Markovic N, Ness RB, Powers RW . Uric acid is as important as proteinuria in identifying fetal risk in women with gestational hypertension. Hypertension. 2005;46:1263-9.

16. Carter J, Child A. Serum uric acid levels in normal pregnancy. Aust N Z J Obstet Gynaecol. 1989;29:313-4.

17. Bulgar HA, Johns HE. The determination of plasma uric acid. J Biol Chem. 1941; 140:427.

18. Browne OT, Bhandais S. Interpreting and investigating proteinuria. BMJ.2012;344:2339.

19. Punthumapol C, Kittichotpanich B. Serum calcium, magnesium and uric acid in preeclampsia and normal pregnancy. J Med Assoc Thai. 2008; 91: 968-73.

20. Suchonda S, Daniel M, Abraham R, Vedavalli $\mathrm{R}$, Senthilvel V. Study of uric acid and nitric oxide concentrations in preeclampsia and normal pregnancy. Int J Biol Med Res. 2011; 2: 390-93.

21. Kharb, S. 2010. S. Uric acid and Ascorbic Acid level in pregnancy with preeclampsia and Diabetes. Web med central BIOCHEMISTRY 2010;1(10):WMC00718.

22. Vyakaranam S, Bhongir A, Patlolla D, Chintapally R. Study of serum uric acid and creatinine in hypertensive disorder of pregnancy. Int J Med Sci Public Health. 2015;4(10):1424-1428.
23. Osakwe CR, Ikpeze OC, Ezebialu IU, Osakwe JO, Mbadugha NN. The predictive value of serum uric acid for the occurance, severity and outcomes of preeclampsia among patients at NNEWI, NIGERIA. Niger J Med 2015 jul-sep; 24(3), 192-200.

24. Toshniwal $\mathrm{S}$ et al. Serum uric acid as marker of severity of preeclampsia.Int J Reprod Contracept Obstet Gynecol. 2017;6: 4915-4917.

25. Dekker GA, Sibai BM. Early prediction of preeclampsia. AM J Obstet Gynecol. 1998;165:160-72.

26. Thangaratinam S, Ismail K, Sharp S. A, Coomarasamy A, Khan KS. Accuracy of serum uric acid in predicting complication of preeclampsia: a systematic review. An international Journal of Obstetric and Gynaecology. 2006;113:369-378.

27. Williams K, Galerneau F. The role of serum uric acid as a prognostic indicator of the severity of maternal and fetal complication in hypertensive pregnancies. J Obstet Gynaecol Can. 2002:24(8):628-32.

28. Tejal P, Astha D. Relationship of Serum Uric Acid Level to Maternal and Perinatal Outcome in Patients with Hypertensive Disorders of Pregnancy. Gujarrat Medical Journal. 2014;9:45-47.

29. Bellomo G. Serum uric acid and preeclampsia: an update. Expert Rev. Cardiovasc. Ther.2012;5(3):00-00.

30. Bellomo G, Venanzi S, Saronio P, Verdura C, Narducci PL. Prognostic significance of serum uric acid in women with gestational hypertension. Hypertension .2011;581(4):704708.

31. Akter S, Sultana S, Dabee SR. Association of Hyperuricemia with perinatal outcome in pregnancy induced hypertension. J Bangladesh Coll Phys Surg. 2014;32:124-129.

32. Zangana JM, Hamadamen AI. Serum Uric Acid as a Predictor of Perinatal Outcome in Women with Pre eclampsia. Int J Med Res Health Sci. 2018;7(3):168-174. 